\title{
"Meron o Wala": A Study on the Usefulness of Twitter during Typhoon as Perceived by the Students of the Selected Intramuros-Based Schools
}

\author{
Kriselle C. Paladin, Kris Anne Jansen R. Ramos, and Rowena Capulong-Reyes
}

\begin{abstract}
Uses and Gratifications theory explains that a person uses a particular kind of media because of the satisfaction a person can get from it. Applied in social media, the current research aims to understand the usefulness of Twitter to the students during typhoon. A total of 124 students from the Intramuros-based schools were selected through a non-probability-purposive sampling. A descriptive analysis was used to measure the answers to a 47 -item questionnaire. They are motivated to use Twitter during typhoon to communicate with their family and friends. The current research found that students use Twitter more whenever there is a typhoon. Students use their mobile phones in logging in to their accounts. The current research also found that Twitter is the students first source of information regarding typhoons and the top information seek by students on Twitter is the announcement of class suspension.
\end{abstract}

Index Terms-Twitter, disaster communication, motivation, satisfaction.

\section{INTRODUCTION}

Social media is significant during the times of calamities and disasters [1]. Disaster communication is been seen to be disseminated via social media. It deals with the spreading of disaster information of governments, emergency management organizations, media and also disaster responders to the public [2].

Microblogging is a form of communication where in users can disseminate their current situation or "status" through short posts instantly by using mobile phones, email or the Web [3].

Twitter is one of the most popular microblogging sites that allow users to share personal information, opinions and status within a 140 character called "tweets" [4]. Users can also "follow" the tweets of other users [5]. It has become a medium to communicate not only with friends but also colleagues, acquaintances, celebrities and interact with organizations, agencies, and even governments [6]. The flood that occurred in Pakistan in the year 2010 emerged as one of the top trending topics on Twitter while 5,500 tweets per second were recorded after the Tsunami happened in Japan in 2011 [7], [8].

According to World Disasters Reports, the Philippines has always been hit by typhoons every year because of its geographic location that it ranked among the top five

Manuscript received September 29, 2013; revised December 2, 2013

Kriselle C. Paladin, Kris Anne Jansen R. Ramos, and Rowena Capulong-Reyes are with the Colegio de San Juan de Letran (e-mail: krisellep@yahoo.com). countries affected by natural disasters.

It has been said that disaster communication is now evident in social media in addition to the coverage made by the traditional media [8]. Television networks in the Philippines are now using Twitter to disseminate information faster. Two of the biggest networks in the country are ABS-CBN and GMA with their Twitter accounts@ANCALERTS or @ ABSCBNNews and @ gmanews respectively.

Even the government organizations and local government are using social media to address announcements to the public. The state weather bureau of the country, the Philippine Atmospheric Geophysical Astronomical Services Administration (PAGASA) issues color signals that signifies the different levels of rain warnings. PAG-ASA also has Twitter account (@dost_pagasa)which allows them to tweet regularly and update their followers of the everyday weather condition.

This study will focus on the usefulness of Twitter during typhoons. It aims to know what account/s people are relying for the announcements of typhoon updates and how this/these account/s give/s satisfaction to the students. The study defines "usefulness" as if the students see and rely on Twitter as the only source of updated information regarding typhoon announcements.

\section{LITERATURE REVIEW}

Academic community is one of the most vulnerable sectors affected by natural disruptions like typhoons and other extreme related events. School administrators, professors, students, teaching and non- teaching staff have variety of procedures in understanding these environmental threats [9].

The Filipino terms 'Meron' and 'Wala' are used in announcing if there is a class suspension and vice versa when heavy rains are evident. The term 'meron' is synonymous to 'may' which means 'have'. It is more pleasant to use 'may' (a possessive verb) to be followed by the noun, 'pasok' (class) which means 'there is a class' in English. On the other hand, the word 'wala' means nothing; therefore 'wala' to be followed by 'pasok' means 'there is no class.' The function of hashtag in Twitter is significant in declaring such class suspension wherein \#maypasok and \#walangpasok are used to easily identify the message of the announcements. These two short and simple terms get the attention of the students after announcing such typhoons updates like storm signal and flooded areas. May pasok and walang pasok are the two much-awaited announcements of 
the local government.

People use social media more actively during the times of calamities [8]. And among the different social media platforms, Twitter is the leading social media service wherein, it becomes more commonly used by the individuals to keep them updated about the news involving disasters [7].

Uses and Gratification Theory aims to know how people use a particular medium to meet their needs and attain satisfaction [10]. One assumption is that people tend to choose their own media depending on the objective they want to achieve. References [1] and [11] say that government organizations as well as universities, and nongovernment organizations are now participating in social media to get in touch with the people, to disseminate information and to invite public discussion.

In a study conducted in 2012, it came out that most of the students who used Twitter during the time of the tornado were most likely those users who visited Twitter at least once a day. Schools created their Twitter account to answer the queries of their students to prevent them from any danger and to assure their security during times of calamities [12].

One advantage of social media is that it may "increase the public's ability to communicate with the government" [13]. The use of Twitter account of the local government unit is very significant for quick dissemination of information. Former Manila City Mayor Alfredo Lim tweeted his announcements regarding typhoon updates and this practice is adopted by the newly elected City Mayor, Joseph Estrada. It is also important that the public is responding to the information the government agency disseminates.

For example, the public published more than 2, 000 related tweets during a fatal storm hitting a festival in Belgium in just half of an hour [14]. That number soared to more than 80, 000 tweets during the first four hours of the disaster. Individuals responded right away to posts made by university spokesperson in the school's official Facebook page [15]. The top users of social networking sites during this time are the younger and college educated individuals [16].

\section{METHODS}

Statistics is used to calculate the data collected for this study. It includes hypotheses, development of instruments and methods for measurements, collection and analysis of data. In this study, survey questionnaire is used to generate categorical data that identify, scale and rank survey statements [17]. There are total of one hundred twenty-four respondents gathered. The sample population is composed of college students in selected schools in Intramuros namely Colegio de San Juan de Letran (CSJL), Lyceum of the Philippines University (LPU), Mapua Institute of Technology (MTI) and Pamantasan ng Lungsod ng Maynila (PLM). Thirty-nine respondents answered the survey in CSJL, twenty-eight in LPU, twenty-five in MTI and thirtytwo in PLM. Intramuros is not prone to floods but the route going there is risky whenever there is a heavy rain. The number of direct routes going to that area is limited but the students have the option to take the pedicab for them to get to their schools. The existence of colleges instituted here is also a factor why did this study focus on this district in Manila. Included in the research are the seven Twitter accounts that are being studied based on the trending accounts during typhoons as being seen in the "\#Discover" button of the microblogging site interface: Manila City Mayor Joseph Estrada (@PresidentErap), Former Manila City Mayor Alfredo Lim (@TheMayorLIM), GMA News (gmanews), ABS-CBN News/ ANC Alerts (ABSCBNEWS, ANCAlerts), Philippine Atmospheric Geophysical Astronomical Services Administration (dost_pagasa), Metro Manila Development Authority (MMDA) and School's official Twitter account.

\section{RESULTS}

Uses and gratifications theory is appropriate in studying social media [12]. The current research used Uses and gratifications theory to further understand the motivations and satisfaction students get from Twitter during typhoons. For H1, the researchers predicted that students are motivated to tweet or participate on Twitter discussions whenever there is a typhoon.

According to researches on social media, people are more active on using different social media when there is a disaster happening as they seek for more useful information [18], [19]. The top reason why the students check their Twitter during typhoon according to the second research question is because they want to know if there is an announcement regarding class suspensions which is also being agreed by $51.61 \%$ (64) of the whole sample in a scale of 1 to 4 . The re-tweeting of announcements about class suspensions was agreed by $50 \%$ (62) of the students. The researchers also asked the respondents whether they view photos, videos and articles linked through Twitter and it resulted to $62.09 \%$ (77) who agreed. Johnson and Young (2009) said that information motivation is getting information, giving or receiving advice and sharing information with others.

One of the reasons why the public would use social media during disasters is to keep in touch with family and friends [3]. In this current research, there is an increase by $12.84 \%$ on Twitter usage to communication with family and friends through Twitter during typhoon compared on a regular day. Whereas there is a difference of $19.35 \%$ between expressing their opinion on Twitter on a regular day and participations Twitter discussions during typhoon. From a study on Twitter motivation where in three stages where analyzed (warning stage, during disaster stage, recovery stage), there is an increase of tweets over the three stages (Maxwell et.al 2012). The motivation to tweet personal updates during typhoon has 58 students who agreed or $46.77 \%$ of the whole sample.

Among 124 respondents, $60.4 \%$ (75) of them agreed that they always get what they are looking for on Twitter regarding typhoon. However, college students from Intramuros do not only rely on Twitter for typhoon updates having $40.32 \%$ (50) from the respondents disagreed with the idea though there is $34.67 \%$ (43) agreed and $11.29 \%$ (14) who strongly agreed on the matter.

Uses and Gratifications Theory says that people know the 
kind of information they want to acquire and thus seek a particular media to meet that need and to be able to aim satisfaction [20]. The current research thus show that the respondents know what they want when the researchers asked the respondents why do they follow or check the accounts they had chosen whenever there is a typhoon. Results show that the respondents follow such accounts (1) to become updated on the announcements (2) to take part in dissemination of information (3) to get involved in the social issues (4) to express opinions (5) to participate in the discussions.

Twitter placed as the top answer having $38.55 \%$ when the respondents were asked where they usually get important announcements. A study revealed that the first information about the earthquake in China in 2008 came from Twitter [21]. A total of $56.45 \%$ (70) respondents agreed while $34.67 \%$ (43) strongly agreed that they benefit from using Twitter therefore achieving satisfaction. Twitter is an effective in disseminating information about typhoon updates, $62.09 \%$ (77). It is also revealed in the results that $50 \%$ (62) of the total sample agree and $27.41 \%$ (34) strongly agreed that they use Twitter whenever there is a typhoon because it is their first source of information and that they are always updated about the country's situation through Twitter with $62.9 \%$ (78) and they also agreed with $45.16 \%$ (56) that Twitter is more updated than any other social media when it comes to information about typhoons.

TABLE I: RANKING OF TWITTER ACCOUNTS ACCORDING TO FIVE FEATURES

\begin{tabular}{llllll}
\hline TWITER & \multicolumn{5}{c}{ FEATURES } \\
ACCOUNTS & Immediacy & Timelimess Accuracy Credibility Exclusivity \\
\hline PresidentErap & 3.23 & 3.40 & 3.73 & 3.60 & 3.65 \\
TheMayorLIM 3.813 .71 & 3.76 & 3.66 & 3.82 & \\
gmanews & 4.15 & 4.36 & 4.25 & 4.44 & 4.22 \\
ABSCBNNews/4.344.36 & 4.33 & 4.19 & 4.07 & \\
ANCAlerts & & & & \\
dost pagasa 4.183.93 & 3.78 & 4.00 & 4.02 & \\
MMDA 3.97 3.77 & 3.86 & 3.65 & 3.54 \\
School's official 4.324 .43 & 4.354 .424 .68 & \\
Twitter account & & & \\
\hline
\end{tabular}

Seven Twitter accounts were ranked by the respondents 1 (one) as the lowest and 5 as the highest through five variables according to immediacy, timeliness, credibility, accuracy, and exclusivity, the accounts' activeness on Twitter were measured. The following features were ranked upon computing the mean. In terms of immediacy, the account of ABS-CBN News/ ANC Alerts ranks number 1 with a mean of 4.34. The school's official Twitter account is the most satisfactory account in terms of timeliness with a mean of 4.43 , accuracy with a mean of 4.35 and exclusivity with a mean of 4.68. And the most credible of all the accounts is GMA News with a mean of 4.44.

School's official Twitter account remains on top for timeliness with a mean of 4 . 43. The accounts of the biggest television networks in the country share the second spot with a mean of 4.36. PAGASA came in third spot with a mean of 3.92. In terms of accuracy, the school's official twitter account is the most satisfactory with a mean of 4.35 . The two accounts of the two biggest television networks in the country ranks consecutively. The account of ABSCBN News/ ANC Alerts ranks number two with a mean of 4.33 while GMA News came in third with a mean of 4.25 .

Respondents find the twitter account of GMA News credible with a mean of 4.44 making it become the most satisfactory. The school's official account came in rank number two with a mean of 4.42. ABSCBN News/ANC Alerts only came in the third spot with a mean of 4.19 followed by the account of PAGASA with 4.00. In terms of exclusivity, respondents see their school's official account to be the most satisfactory with a mean of 4.68. GMA and ABSCBN compete for exclusivity but GMA is more satisfactory than ABSCBN with a mean of 4.22 while ABSCBN has a mean of 4.07 .

\section{CONCLUSION}

A quantitative method through a survey questionnaire and descriptive analysis was made after the typhoons Labuyo, Maring and Habagat came in the Philippines in August 18, 2013. Classes were suspended inside and outside Metro Manila with exceptions on August 12-13 due to Typhoon Labuyo with an international name, Utor. One week after, classes were again suspended for not more than five days because of the Severe Tropical Storm Maring (Trami) and Habagat.

Twitter was used effectively during those times as one of the main source of information. The results show that there are more students who tweet several times whenever there is a typhoon but the students are more active on twitter by just checking on the latest updates and not much on expressing opinions and participating in the discussions. The top two reasons why students follow the given accounts is to take part in dissemination of information through re-tweeting it and by sharing personal updates. They use Twitter by following accounts that can give them updated information about the typhoon. They are motivated to tweet so that they could communicate with their family and friends and know if there is an announcements regarding class suspension and know if there is an announcements regarding class suspension. Therefore it is acceptable to say that students are more active in tweeting and participating in Twitter discussions whenever there is a typhoon.

The consistent top three accounts when the researchers measured immediacy, timeliness, accuracy, credibility, and exclusivity are the Twitter accounts of ABS-CBN, GMA and the students' school Twitter account.

The current research did not just study Twitter as a whole as a medium of communication, the current research also identify the top accounts that students prefer to check to get information that is immediate, timely, accurate, credible and exclusive. This could help improve the Twitter accounts of the schools in Intramuros, Manila regarding using Twitter as a medium of communication during typhoon. However, the limitation of the study is that it only considers a particular disaster which is typhoon because every disaster is different just like every kind of social media.

Future research could also focus more on the use of the 
Twitter account of a Local Government Unit for its effectiveness in disseminating information or updates during typhoon or any kind of disaster through the use of Twitter to further understand its usefulness.

\section{REFERENCES}

[1] E. Goldfine. (2011). Best Practices: The Use of Social Media throughout Emergency and Disaster Relief. [Online]. Available: http://www.american.edu/soc/communication/upload/EricaGoldfine.pdf

[2] J. Fraustino, Y. Jin, and B. Liu, "Social media use during disasters: a review of the knowledge base and gaps," Final Report to Human Factors/Behavioral Sciences Division, Science and Technology Directorate, U.S. Department of Homeland Security, College Park, MD: START, 2012.

[3] Java et al., "Why we twitter: understanding microblogging usage and communities," in Proc. the Joint 9th WEBKDD and 1st SNA-KDD Workshop, 2007.

[4] J. Pontin, "From many tweets, one loud voice on the internet," The New York Times, 2007

[5] D. Pogue. (2009, February 11). Twitter? It's what you make it, The New York Times. [Online]. Available: http://www.nytimes.com/2009/02/12/technology/personaltech/12pogu e.html

[6] J. Labor, P. Galace, and D. Pacardo, "Gatekeeping PAG-ASA: communication behavior and process of weather bureau twitter accountholders," Luz y Saber, vol. 7, no. 1, pp. 35-50, 2012.

[7] D. Murthy and S. Longwell, "Twitter and Disasters: the uses of Twitter during the 2010 Pakistan floods," Conference Papers-International Communication Association, Annual Meeting, pp. 1-30, 2012.

[8] N. A. (2012). Social media use during disasters. A Review of the Knowledge Base and Gaps. National Consortium for the Study of Terrorism and Responses to Terrorism A Department of Homeland Security Science and Technology Center of Excellence Based at the University of Maryland. [Online]. Available: http://www.start.umd.edu

[9] A. Salva and G. Banaguas, "University-based disaster risk management (UBDRM) for De La Salle Araneta University," Lagumlalang: A Refereed Journal of Interdisciplinary Synthesis, vol. 1 , no. 2,2012

[10] W. Severin and J. Tankard, Communication Theories: Origins, Methods, and Uses in the Mass Media, (5th ed.), New York: Longman, 2001.

[11] B. Lindsay, "Social Media and Disasters: Current Uses, Future Options and Policy Considerations," Journal of Current Issues in Media \& Telecommunications, vol. 2, iss. 4, pp. 287-297, 2011.

[12] E. M. Maxwell et al., (2012). "Motivations to tweet: A uses and gratifications perspective of twitter use during a natural disaster," [Online]. Available: http://www.acumen.lib.ua.edu/content/u0015/.../u0015_0000001_000 1027.pdf

[13] C. Fugate, "Understanding the power of social media as a communication tool in the aftermath of disasters," 112th Cong., 1st 2011.

[14] Perng et al., "Peripheral response: Microblogging during the 22/7/2011 Norway attacks," in Proc. the 9th International ISCRAM Conference, Vancouver, Canada, 2012.
[15] M. Formentin, D. Bortree, and J. D. Fraustino, "Navigating anger in happy valley: using facebook for crisis response and image repair in the wake of the Sandusky scandal," presented at the meeting of the Association for Education in Journalism and Mass Communication, Chicago, IL, 2012

[16] S. D. Smith. (2010). Research Study. ECAR study of undergraduate students and information technology. Boulder. CO: EDUCAUSE Center for Applied Research. [Online]. 6. Available: http://www.educause.edu/Resources/ECARStudyofUndergraduateStu den $/ 217333$

[17] N. A. (2010). Introduction to Quantitative research. [Online] Available: http://www.sagepub.com/upm-data/36869_muijs.pdf

[18] L. Bates and C. Callison. (2008, August). Effect of company affiliation on credibility in the blogosphere. Retrieved 17 Feb, 2013 [Online]. Available: http://www.aejmc.org/home/2011/03/pr-2008

[19] K. D. Sweetser and E. Metzgar, "Communicating during crisis: Use of blogs as a relationship management tool," Public Relations Review, vol. 33, pp. 340-342, 2007.

[20] E. Katz, J. G. Blumer, and M. Gurevitch, "Utilization of Mass Communication by the Individual," in the Uses of Mass Communications: Current Perspectives on Gratifications Research, J. G. Blumer and E. Katz (Eds.), pp. 19-32, Beverly Hills, CA: Sage Publications, 1974.

[21] Mills et al., (2009). Web 2.0 emergency applications: How useful can Twitter be for an emergency response? [Online]. Available: http://denman-

mills.net/web_documents/jips_mills.etal._2009.07.22_finalsubmissio n.pdf

Kriselle Paladin was born on July 4, 1994 in Quezon City, Philippines She graduated elementary in Caloocan Elementary School Central and her secondary in Caloocan High School. She's currently on her senior year in tertiary school finishing a degree of AB Communication Arts at Colegio de San Juan de Letran-Manila.

Kriselle Paladin was an editor of an explanatory report about the Cybercrime in the Philippines. She has won several awards on Communication including the Best Policy Paper in promoting Letranism and Best Student athlete. She with her collegues had nominated in Araw Values Award and Jes Comm for her team's Radio PSA

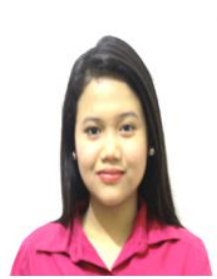

Kris Anne Jansen Ramos was born on January 4, 1994 in Manila. She spent her formative years in Hagonoy, Bulacan in the Philippines. She is currently in her senior year taking up Bachelor of Arts Major in Communication Arts in Colegio de San Juan de Letran, located in Intramuros, Manila. She co-wrote an explanatory report about the plastic use regulation in selected cities in the Philippines. She was once a writer for her college departmen community newspaper.

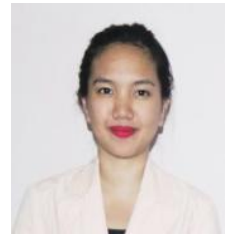

Kris Anne Jansen Ramos won in the annual awards for communication excellence in her schoo for her teleplay script together with her two colleagues. She was also a finalist in the Araw Values Awards and JesCom Young Visionaries Media Competition in 2012 for her radio public service announcement. 